\title{
Dysregulation of GTPase IMAP family members in hepatocellular cancer
}

\author{
ZHEN HUANG $^{1 *}$, WEI ZHANG ${ }^{2 *}$, CHUNHAI GAO $^{3}$, BAOJU JI $^{3}$, \\ XIUWEN $\mathrm{CHI}^{4}$, WEI ZHENG ${ }^{5}$ and HAI LAN WANG ${ }^{6}$ \\ ${ }^{1}$ Department of Laboratory Medicine, Longgang District Central Hospital, Shenzhen, Guangdong 518116; \\ ${ }^{2}$ Second Department of Trauma Orthopedics; ${ }^{3}$ Department of Laboratory Medicine, Linyi People's Hospital, \\ Linyi, Shandong 276003; ${ }^{4}$ School of Nursing, Guangdong Medical College, Dongguan, Guangdong 523808; \\ Departments of ${ }^{5}$ Emergency Teaching and Research, and ${ }^{6}$ Endocrinology Teaching and Research, \\ Longgang District Central Hospital, Shenzhen, Guangdong 518116, P.R. China
}

Received July 20, 2015; Accepted May 13, 2016

DOI: $10.3892 / \mathrm{mmr} .2016 .5764$

\begin{abstract}
Hepatocellular carcinoma (HCC) is one of the most life-threatening diseases in the world. Members of the GTPase of the immunity-associated protein (GIMAP) family are important in regulating apoptosis in cancer cells. However, the basic mechanism of GIMAP in HCC remains to be fully elucidated. The present study was performed to investigate the dysregulation of GIMAP family members in HCC. The techniques of polymerase chain reaction analysis, immunohistochemistry and ELISA were used to analyze the expression of GIMAP5 and GIMAP6 in HCC tissues, in matched noncancerous tissue samples, and in blood samples obtained from patients with HCC and healthy subjects. It was found that the mRNA expression levels of GIMAP5 and GIMAP6 were significantly downregulated in the HCC tumor samples, compared with the levels of expression in the matched non-tumor tissue samples. Similarly, the mRNA expression levels of GIMAP5 and GIMAP6 were also significantly downregulated in the blood samples from patients with HCC, compared with the expression levels in the blood from healthy subjects. At the protein level, it was found that the GIMAP5 and GIMAP6 proteins were expressed at lower levels in the tumor tissue samples, compared with the matched normal tissue samples, and their expression levels were also lower in the blood samples from patients with HCC, compared with the blood samples from the
\end{abstract}

Correspondence to: Professor Hai Lan Wang, Department of Endocrinology Teaching and Research, Longgang District Central Hospital, 6082 Longgang Road, Shenzhen, Guangdong 518116, P.R. China

E-mail: huangzh1976@126.com

*Contributed equally

Key words: GTPase of the immunity-associated protein 5, GTPase of the immunity-associated protein 6 , hepatocellular carcinoma, dysregulation, downregulation healthy subjects. These data, demonstrating the downregulation of the mRNA and protein expression levels of GIMAP5 and GIMAP6 in the tumor tissues and blood of patients with HCC, suggested the involvement of GIMAP5 and GIMAP6 in the pathogenesis of $\mathrm{HCC}$, and indicate their possible use as diagnostic markers for $\mathrm{HCC}$.

\section{Introduction}

Hepatocellular carcinoma (HCC) is one of the most common malignancies and the second leading cause of cancer-associated mortality worldwide (1). The highest incidences of HCC are found in Africa and Asia, including China (2,3), and the majority of cases are associated with a past or concurrent chronic hepatitis B or hepatitis $\mathrm{C}$ infection, alcohol abuse or aflatoxin B1 exposure (4). Although treatments for HCC are evolving, surgery remains the most preferred and effective modality for treating HCC. Although liver transplantation is also a treatment option, the shortage of donated organs limits its wider application in clinical practice. Other therapeutic measures, including chemotherapy and transcatheter arterial chemoembolization have been used to treat HCC, but have failed to produce an observable effect (5). Therefore, increased knowledge concerning the underlying mechanisms of the tumorigenesis and/or progression of HCC is urgently required to identify an effective method for managing patients with $\mathrm{HCC}$.

It is widely accepted that genetic and epigenetic alterations, including gene amplifications and mutations, chromosomal translocations and non-coding RNAs, are associated with HCC tumorigenesis (6), and mutations in several specific genes, including tumor protein 53, $\beta$-catenin (7) and sirtuin 1 (8), are reported to be associated with the development and progression of HCC. In addition, next generation sequencing techniques have revealed possible roles for additional mutations in genes, including low density lipoprotein receptor-related protein 1B (9), interferon regulatory factor 2 (10) and AT-rich interactive domain 1A (11). However, the scientific value of the majority of previous reports regarding genetic involvement in HCC have been limited by small sample numbers or the use of outdated analytical techniques. Therefore, the possible involvement of 
other gene abnormities in the development of $\mathrm{HCC}$ requires consideration. The GTPase of the immunity-associated protein (GIMAP) gene family is known to contribute to the pathogenesis of non-small cell lung cancer (NSCLC) and the immune reaction mounted against it (12); however, this gene family has not been investigated with regards to its possible roles in $\mathrm{HCC}$.

In the present study, the techniques of reverse transcription-quantitative polymerase chain reaction (RT-qPCR) analysis, immunohistochemistry (IHC) and ELISA were used to compare the proteins and mRNA found in samples of HCC tissue and matched samples of non-cancerous tissue, and found that the mRNA and protein levels of GIMAP5 and GIMAP6 were downregulated in the HCC tumor tissue samples. Additionally, when comparing the mRNA and protein levels of GIMAP5 and GIMAP6 in samples of blood obtained from normal subjects and patients with HCC, similar results were found. The identification of these downregulated levels of GIMAP family members may contribute to an improved understanding of the molecular mechanisms involved in the development and progression of HCC, and may lead to future clinical applications for GIMAP5 and GIMAP6.

\section{Materials and methods}

Patients. Between December 2011 and December 2013, samples of blood and liver tissues were collected from 60 patients (44 males and 36 females; mean age, 55.4 years; range, 18-76 years) who had been diagnosed with HCC, based on criteria used by the American Association for the Study of Liver Diseases (www.aasld.org). The protocol for the present study was approved by the ethics committee of Longgan Hospital (Shenzhen, China), which also waived the requirement to obtain informed consent from the tissue donors.

Serum collection and storage. Samples of blood $(10 \mathrm{ml})$ were collected from patients with HCC and normal control subjects, placed into labeled tubes and allowed to clot for $30 \mathrm{~min}$ at room temperature. The blood was centrifuged for $5 \mathrm{~min}$ at $3,000 \mathrm{~g}$ and $4^{\circ} \mathrm{C}$, following which, $0.5 \mathrm{ml}$ aliquots of serum were transferred into tubes and labeled. The serum was then frozen immediately, ideally within $10 \mathrm{~min}$ of aliquoting, and stored at $-80^{\circ} \mathrm{C}$ until further use.

RNA extraction. Tissue samples were homogenized in $50 \mathrm{mM}$ Tris-HC1 ( $\mathrm{pH} 7.5$ ) and centrifuged at 2,500 x $\mathrm{g}$ for $5 \mathrm{~min}$. TRIzol reagent (Sigma-Aldrich, St. Louis, MO, USA) was used to isolate total RNA from the samples of HCC cancer tissue and the serum of patients with HCC, according to the manufacturer's protocol. Control sample RNA was purchased from Ambion, Inc. (Austin, TX, USA) and BioChain Institute, Inc. (Newark, CA, USA). RNA quality was assessed using an Agilent Bioanalyzer 2100 (Agilent Technologies, Inc. Palo Alto, CA, USA), and RNA samples with integrity scores $>5$ were subjected to RT-qPCR analysis.

$R T$ - $q P C R$. cDNA templates of different genes were obtained by RT of the RNA using Super M-MLV RT (BioTeke Corporation, Beijing, China), and the final reaction mixture of volume $20 \mu \mathrm{l}$ contained $10 \mu \mathrm{l}$ of $2 \mathrm{X}$ Taq PCR Master-mix (BioTeke Corporation), $1 \mu \mathrm{l}$ of each primer (GIMAP5, forward 5'-CAT
GTTAGGGAAGCTCAGTC-3', reverse 5'-GAAGGGTTC TACTGTGTCTCA-3'; GIMAP6, forward 5'-TGGATG CTCTGGATGTTGCA-3', reverse 5'-TCCTGCTCATCC CCTTGTG-3'; hypoxanthine phosphoribosyltransferase 1 (HPRT1), forward 5'-GACCAGTCAACAGGGGACAT-3', reverse 5'-GTGTCAATTATATCTTCCACAATCAAG-3'), $1 \mu \mathrm{l}$ cDNA template and $7 \mu \mathrm{l}$ of RNase free $\mathrm{H}_{2} \mathrm{O}$. Thermal cycling parameters for the amplification were as follows: Denaturation step, $95^{\circ} \mathrm{C}$ for $5 \mathrm{~min}$; followed by 36 cycles at $95^{\circ} \mathrm{C}$ for $20 \mathrm{sec}, 52^{\circ} \mathrm{C}$ for $20 \mathrm{sec}$ and $72^{\circ} \mathrm{C}$ for $30 \mathrm{sec}$; and the reaction was stopped by a step at $25^{\circ} \mathrm{C}$ for $5 \mathrm{~min}$. The relative expression level of the targeted genes was normalized to HPRT1 according to the $2^{-\Delta \Delta \mathrm{Cq}}$ method (13).

IHC. The samples of the HCC and matched normal tissues were fixed in formalin and embedded in paraffin. Subsequently, 4- $\mu \mathrm{m}$ sections of the 60 paraffin-embedded HCC tumor tissue samples and matched non-tumor tissue samples were deparaffinized in xylene, rehydrated in an alcohol series and washed in distilled water. The sections were then treated by microwave for antigen retrieval for $8 \mathrm{~min}$ at $450 \mathrm{~W}$, and incubated with serum-free blocking reagent (Dako, Carpentaria, CA, USA) for $10 \mathrm{~min}$ at room temperature to inhibit non-specific staining. Subsequently, the slides mounted with the tissue sections were incubated with rabbit anti-GIMAP5 (1:200; cat. no. ab74575; Abcam, Cambridge, MA, USA) or rabbit anti-GIMAP6 (1:200; cat. no. ab126067; Abcam) antibodies in a humid chamber overnight at $4^{\circ} \mathrm{C}$. After three 5 min washes with $0.01 \mathrm{M}$ phosphate-buffered saline (PBS), goat anti-rabbit secondary antibody (1:200; cat. no. A0277; Beyotime Institute of Biotechnology, Jiangsu, China) was added to the sections and incubated at $37^{\circ} \mathrm{C}$ for $30 \mathrm{~min}$ prior to five PBS washes. Peroxidase activity was detected using the enzyme substrate, 3,3 N-diaminobenzidine tertrahydrochloride. Scores of the immunohistochemical assay was determined by scanning the slides using an Aperio ScanScope GL (Leica Microsystems $\mathrm{GmbH}$, Wetzlar, Germany) at x400 magnification. ImageScope software (Leica Microsystems $\mathrm{GmbH}$ ) was then used to assess the scanned images based on the percentage of positively stained cells and the staining intensity. Scores for the expression levels of GIMAP5 and GIMAP6 were based on the staining intensity and the percentage of positively-stained cells, as follows: $0,0-9 \%$ of cells stained positive; $1,10-29 \%$ of cells stained positive; 2, 30-69\% of cells stained positive; $3,70-100 \%$ of cells stained positive.

Statistical analysis. All data were analyzed using Prism 5 software (GraphPad Software Inc., La Jolla, CA, USA). All values are presented as the mean \pm standard error of the mean, obtained from analyses of three independent experiments. Differences between groups were analyzed using the non-paired Student's two-tailed $t$-test. $\mathrm{P}<0.05$ was considered to indicate a statistically significant difference.

\section{Results}

mRNA expression levels of GIMAP5 and GIMAP6 in HCC tissues and matched non-tumor tissues. As shown in Fig. 1A, the mRNA expression of GIMAP5 was significantly downregulated in the $30 \mathrm{HCC}$ tissue samples, compared with the 
A

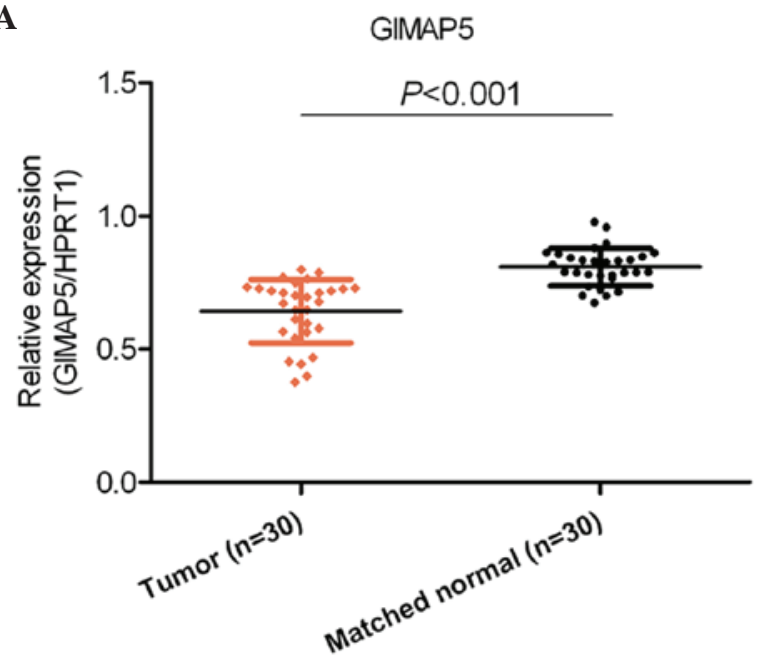

B

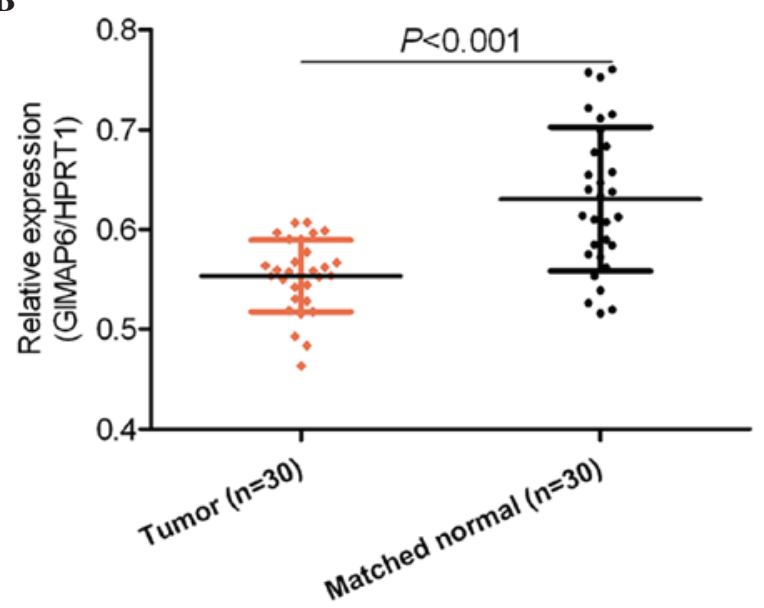

A

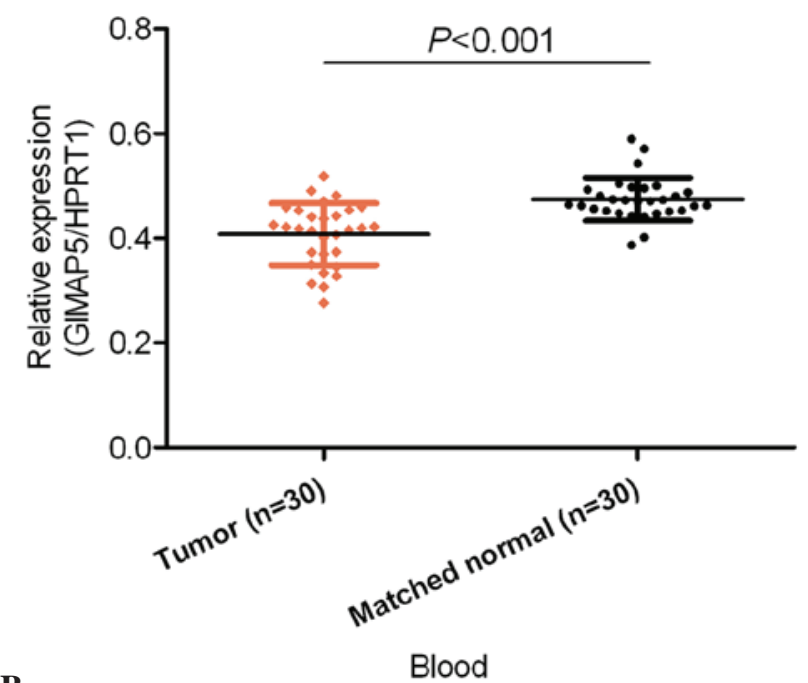

B

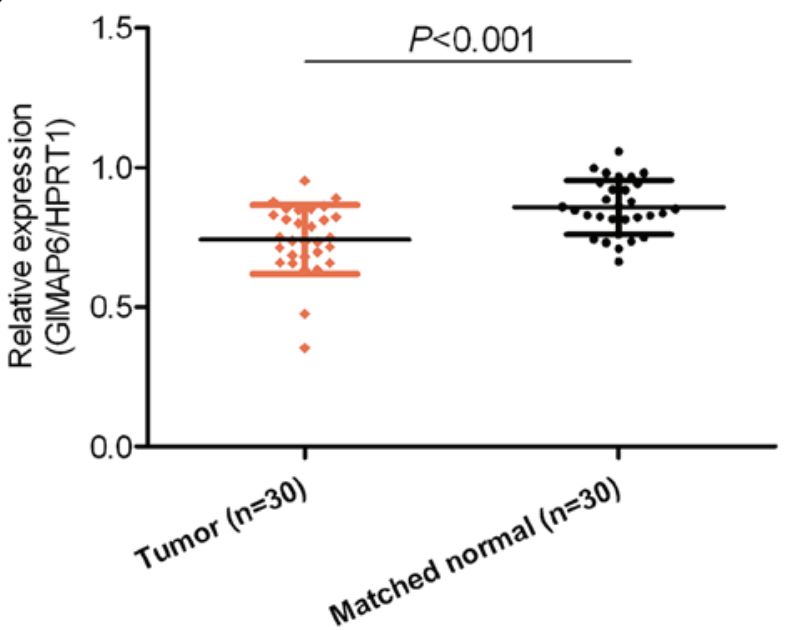

Figure 1. mRNA expression levels of GIMAP5 and GIMAP6 in samples of HCC tissue and adjacent matched non-tumor tissue. mRNA expression of (A) GIMAP5 and (B) GIMAP6 in 30 pairs of HCC tissue and matched non-tumor tissue samples, as determined using reverse transcription-quantitative polymerase chain reaction analysis. Values are presented as the mean \pm standard error of the mean. HCC, hepatocellular carcinoma; GIMAP, GTPase of the immunity-associated protein; HRPT1, hypoxanthine phosphoribosyltransferase 1 .

30 samples of adjacent matched non-tumor tissues $(\mathrm{P}<0.001)$. Similar results were shown for the expression of GIMAP6 in another set of $30 \mathrm{HCC}$ tissues and 30 samples of adjacent non-cancerous tissue $(\mathrm{P}<0.001$; Fig. $1 \mathrm{~B})$. These results indicated that GIMAP5 and GIMAP6 were dysregulated at the mRNA level in HCC tissues, and this dysregulation may be involved in the pathogenesis of HCC.

mRNA expression levels of GIMAP5 and GIMAP6 are downregulated in the serum of patients with HCC. Dysregulation of mRNA may or may not be reflected in the blood of patients. Therefore, the present study examined the mRNA expression levels of GIMAP5 and GIMAP6 in the serum of blood from patients with HCC and healthy control subjects. It was found that the mRNA expression levels of GIMAP5 and GIMAP6 were significantly downregulated in the blood of the patients with HCC, compared with their expression levels in the blood of the normal healthy subjects $(\mathrm{P}<0.001$; Fig. 2$)$.

Figure 2. mRNA expression levels of GIMAP5 and GIMAP6 in the serum of patients with HCC and of normal subjects. mRNA expression of (A) GIMAP5 and (B) GIMAP6 in the serum of 30 patients with HCC and 30 healthy control subjects, determined using reverse transcription-quantitative polymerase chain reaction analysis. Values are presented as the mean \pm standard error of the mean. HCC, hepatocellular carcinoma; GIMAP, GTPase of the immunity-associated protein; HRPT1, hypoxanthine phosphoribosyltransferase 1 .

Protein expression of GIMAP5 and GIMAP6 in tissue samples. The present study subsequently examined whether the dysregulation observed in the mRNA expression of GIMAP5 and GIMAP6 were also observed in the respective proteins. The IHC examinations of the protein expression levels of GIMAP5 and GIMAP6 revealed results that were consistent with the results for mRNA expression, with the protein levels of GIMAP5 and GIMAP6 being downregulated in the HCC tissue samples, compared with their levels in the samples of adjacent normal tissue $(\mathrm{P}<0.001$; Fig. 3$)$. These results suggested that the GIMAP5 and GIMAP6 proteins may offer potential as diagnostic biomarkers for HCC.

Protein expression of GIMAP5 and GIMAP6 in the serum of patients with HCC and normal control subjects. The present study also examined the protein expression of GIMAP5 and GIMAP6 in the blood of patients with HCC using ELISA. 


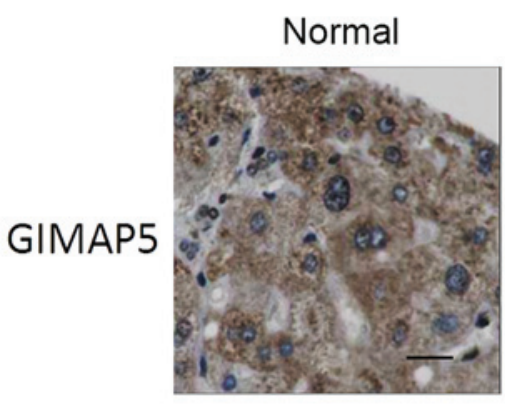

B

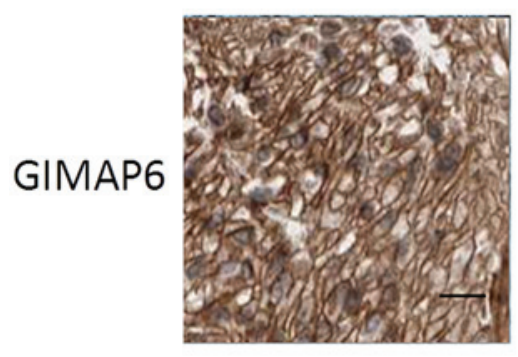

$\mathrm{HCC}$
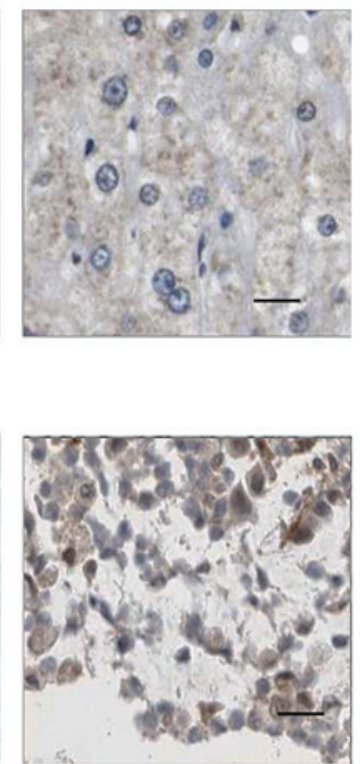

GIMAP5

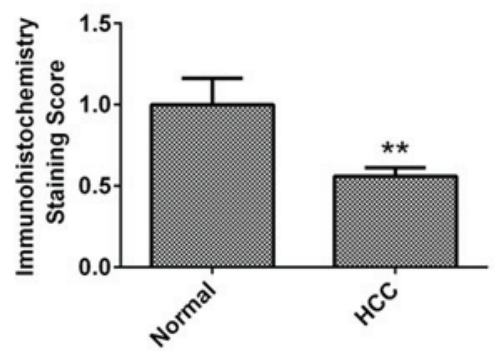

GIMAP6

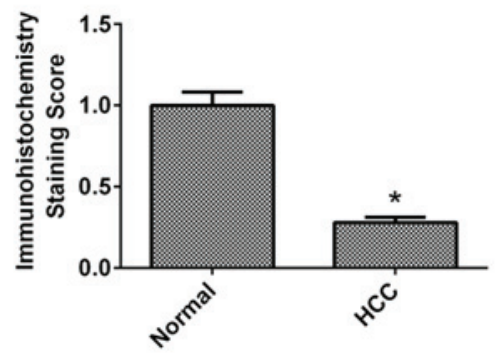

Figure 3. Protein expression levels of GIMAP5 and GIMAP6 in samples of HCC tissue and adjacent non-tumor tissue. Representative images showing the relative protein expression of (A) GIMAP5 and (B) GIMAP6 in 30 pairs of HCC and adjacent non-tumor tissue samples, as determined using immunohistochemical analysis. Scale bar, $100 \mu \mathrm{m} .{ }^{*} \mathrm{P}<0.01,{ }^{* *} \mathrm{P}<0.05$ vs. normal. HCC, hepatocellular carcinoma; GIMAP, GTPase of the immunity-associated protein.
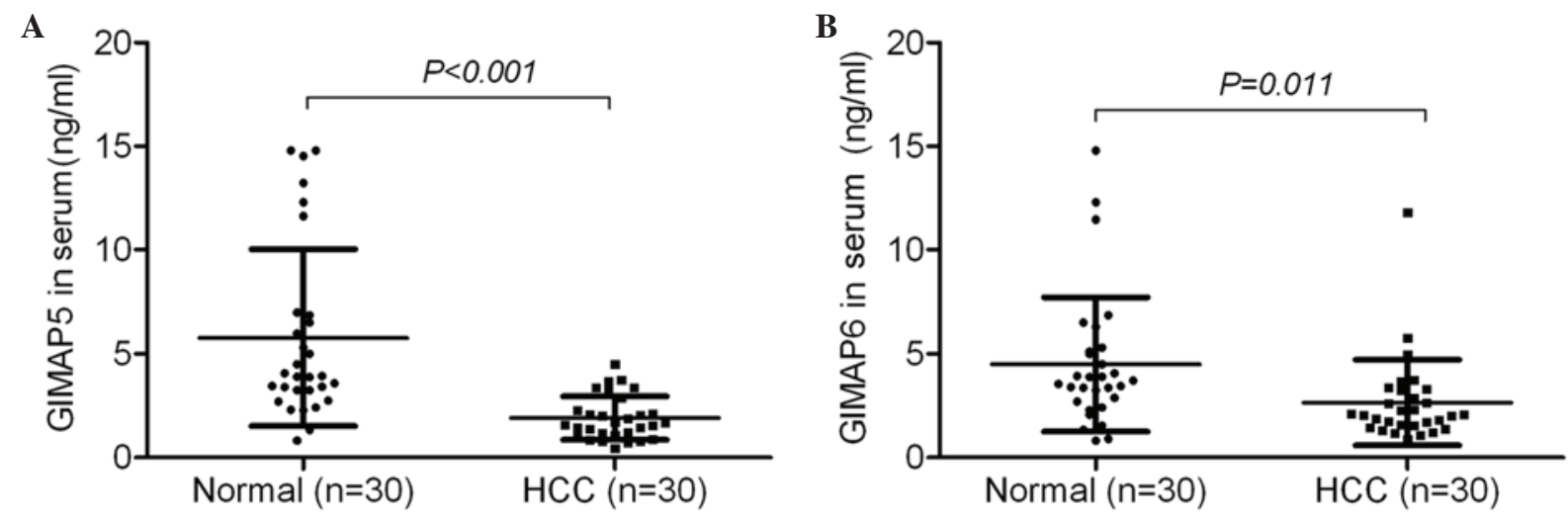

Figure 4. Protein expression levels of GIMAP5 and GIMAP6 in the serum of patients with HCC and normal control subjects. Protein expression of (A) GIMAP5 and (B) GIMAP6 in the serum of 30 pairs of patients with $\mathrm{HCC}$ and 30 healthy control subjects, as determined using ELISA. Values are presented as the mean \pm standard error of the mean. HCC, hepatocellular carcinoma; GIMAP, GTPase of the immunity-associated protein.

It was found that the GIMAP5 and GIMAP6 proteins were expressed at lower levels in the blood of the patients with HCC, compared with the expression levels in the blood of healthy control subjects $(\mathrm{P}<0.001$; Fig. 4), providing further confirmation of the lower expression levels of GIMAP5 and GIMAP6 in the tissues and blood of patients with HCC.

\section{Discussion}

GIMAPs are a family of putative small GTPase proteins, which are conserved in vertebrates and plants (14). This family comprises seven proteins, which have their coding genes residing on human chromosome 7 (12). These GIMAP family members have unique primary structures, and thus represent a novel family of $G$ proteins. Previous studies have shown that GIMAPs are expressed at the highest levels in cells of the immune system (15), therefore, the majority of reports have associated them with immunological functions and immune disorders $(16,17)$. In addition, certain studies have demonstrated GIMAP dysregulation in a number of tumors, suggesting their potential functions in tumorigenesis $(12,18)$. To extend current knowledge of the GIMAP family members associated with HCC, the present study investigated the expression of GIMAP5 and GIMAP6 in samples of HCC tissue and in serum obtained from patients with HCC.

GIMAP5 is the member of the GIMAP family, which has received the most attention. Dalberg et al (19) found that reduced expression of GIMAP5 in Jurkat cells did not affect the number of apoptotic cells, whereas transient overexpression of GIMAP5 resulted in a significant increase in the number of 
apoptotic cells; suggesting that the overexpression of GIMAP5 is important for inducing $\mathrm{T}$ cell apoptosis (19). In a study by Hellquist et al (20), genetic variation in GIMAP5 was found to be involved in the susceptibility to systemic lupus erythematosus. In addition, Shiao et al (12) compared NSCLC tissues with adjacent non-tumor tissues, and found that all GIMAP members, including GIMAP5, were expressed at lower levels in the NSCLC tissues, suggesting their potential function in NSCLC tumorigenesis (12). In the present study, it was found that the expression of GIMAP5 was downregulated in the tumor tissues and blood samples obtained from patients with $\mathrm{HCC}$, suggesting its involvement in the pathogenesis of HCC, as well as its potential as a diagnostic biomarker for HCC.

Pascall et al (21) showed that the interaction between GIMAP6 and autophagy-related protein 8 is crucial for autophagy (21). Additionally, GIMAP6 was found to be downregulated in samples of NSCLC tissue, compared with normal tissue (12). Knowledge regarding the function of GIMAP6 in cells remains limited. In the present study, it was found that the expression levels of GIMAP6 and GIMAP5 were downregulated in HCC tissues, compared with adjacent non-tumor tissues, which suggested their potential functions in the development and progression of HCC. Consistent with these findings, the expression of GIMAP6 was also downregulated in the serum of patients with HCC, suggesting its potential future diagnostic application. These results were confirmed at the mRNA and protein expression levels.

In conclusion, the present study found that the mRNA and protein expression levels of GIMAP5 and GIMAP6 were downregulated in samples of HCC tissue and in serum obtained from patients with HCC, suggesting the potential application of these two biomarkers in diagnostic procedures. Further investigations into the feasibility of using GIMAP5 and GIMAP6 as biomarkers for HCC are required.

\section{Acknowledgements}

This study was supported by the National Natural Science Foundation of PR. China (grant nos. 81201831 and 81301882), the Medical Science and Technology Research Project of Guangdong Province (grant no. B2012266) and the Fundamental Research Funds for the Central Universities (grant no. 20620140118).

\section{References}

1. Ferlay J, Shin HR, Bray F, Forman D, Mathers C and Parkin DM: Estimates of worldwide burden of cancer in 2008: GLOBOCAN 2008. Int J Cancer 127: 2893-2917, 2010.

2. Hao C, Zhu PX, Yang X, Han ZP, Jiang JH, Zong C, Zhang XG, Liu WT, Zhao QD, Fan TT, et al: Overexpression of SIRT1 promotes metastasis through epithelial-mesenchymal transition in hepatocellular carcinoma. BMC Cancer 14: 978, 2014.

3. Goh LY, Leow AH and Goh KL: Observations on the epidemiology of gastrointestinal and liver cancers in the Asia-Pacific region. J Dig Dis 15: 463-468, 2014.
4. Jemal A, Bray F, Center MM, Ferlay J, Ward E and Forman D: Global cancer statistics. CA Cancer J Clin 61: 69-90, 2011.

5. Cauchy F, Fuks D and Belghiti J: HCC: Current surgical treatment concepts. Langenbecks Arch Surg 397: 681-695, 2012.

6. Woo HG, Kim SS, Cho H, Kwon SM, Cho HJ, Ahn SJ, Park ES, Lee JS, Cho SW and Cheong JY: Profiling of exome mutations associated with progression of HBV-related hepatocellular carcinoma. PLoS One 9: e115152, 2014.

7. Laurent-Puig P, Legoix P, Bluteau O, Belghiti J, Franco D, Binot F, Monges G, Thomas G, Bioulac-Sage P and Zucman-Rossi J: Genetic alterations associated with hepatocellular carcinomas define distinct pathways of hepatocarcinogenesis. Gastroenterology 120: 1763-1773, 2001.

8. Chen J, Zhang B, Wong N, Lo AW, To KF, Chan AW, Ng MH, Ho CY, Cheng SH, Lai PB, et al: Sirtuin 1 is upregulated in a subset of hepatocellular carcinomas where it is essential for telomere maintenance and tumor cell growth. Cancer Res 71: 4138-4149, 2011.

9. Ding D, Lou X, Hua D, Yu W, Li L, Wang J, Gao F, Zhao N, Ren G, Li L and Lin B: Recurrent targeted genes of hepatitis B virus in the liver cancer genomes identified by a next-generation sequencing-based approach. PLoS Genet 8: e1003065, 2012.

10. Guichard C, Amaddeo G, Imbeaud S, Ladeiro Y, Pelletier L, Maad IB, Calderaro J, Bioulac-Sage P, Letexier M, Degos F, et al: Integrated analysis of somatic mutations and focal copy-number changes identifies key genes and pathways in hepatocellular carcinoma. Nat Genet 44: 694-698, 2012.

11. Fujimoto A, Totoki Y, Abe T, Boroevich KA, Hosoda F, Nguyen HH, Aoki M, Hosono N, Kubo M, Miya F, et al: Whole-genome sequencing of liver cancers identifies etiological influences on mutation patterns and recurrent mutations in chromatin regulators. Nat Genet 44: 760-764, 2012.

12. Shiao YM, Chang YH, Liu YM, Li JC, Su JS, Liu KJ, Liu YF, Lin MW and Tsai SF: Dysregulation of GIMAP genes in non-small cell lung cancer. Lung Cancer 62: 287-294, 2008.

13. Livak KJ and Schmittgen TD: Analysis of relative gene expression data using real-time quantitative PCR and the 2(-Delta Delta C(T)) Method. Methods 25: 402-408, 2001

14. Nitta T and Takahama Y: The lymphocyte guard-IANs: Regulation of lymphocyte survival by IAN/GIMAP family proteins. Trends Immunol 28: 58-65, 2007.

15. Filen S and Lahesmaa R: GIMAP proteins in T-lymphocytes. J Signal Transduct 2010: 268589, 2010.

16. Yano K, Carter C, Yoshida N, Abe T, Yamada A, Nitta T, Ishimaru N, Takada K, Butcher GW and Takahama Y: Gimap3 and Gimap5 cooperate to maintain T-cell numbers in the mouse. Eur J Immunol 44: 561-572, 2014.

17. Saunders A, Webb LM, Janas ML, Hutchings A, Pascall J, Carter C, Pugh N, Morgan G, Turner M and Butcher GW: Putative GTPase GIMAP1 is critical for the development of mature B and T lymphocytes. Blood 115: 3249-3257, 2010.

18. Zenz T, Roessner A, Thomas A, Fröhling S, Döhner H, Calabretta B and Dahéron L: HIan5: The human ortholog to the rat Ian4/Iddm1/lyp is a new member of the Ian family that is overexpressed in B-cell lymphoid malignancies. Genes Immun 5: 109-116, 2004.

19. Dalberg U, Markholst H and Hornum L: Both Gimap5 and the diabetogenic BBDP allele of Gimap5 induce apoptosis in T cells. Int Immunol 19: 447-453, 2007.

20. Hellquist A, Zucchelli M, Kivinen K, Saarialho-Kere U, Koskenmies S, Widen E, Julkunen H, Wong A, Karjalainen-Lindsberg ML, Skoog T, et al: The human GIMAP5 gene has a common polyadenylation polymorphism increasing risk to systemic lupus erythematosus. J Med Genet 44: 314-321, 2007.

21. Pascall JC, Rotondo S, Mukadam AS, Oxley D, Webster J, Walker SA, Piron J, Carter C, Ktistakis NT and Butcher GW: The immune system GTPase GIMAP6 interacts with the Atg8 homologue GABARAPL2 and is recruited to autophagosomes. PLoS One 8: e77782, 2013. 